\title{
Author Correction: Natural product anticipation through synthesis
}

Belinda E. Hetzler(D), Dirk Trauner(D) and Andrew L. Lawrence (i)

Correction to: Nature Reviews Chemistry https://doi.org/10.1038/s41570-021-00345-7, published online 14 January 2022.

In the text and in Fig. 6 a of the originally published version, we inadvertently misnamed the corresponding authors of ref. ${ }^{64}$. This has now been corrected in all versions of the article.

https://doi.org/10.1038/s41570-022-00374-w I Published online 22 February 2022

๑) Springer Nature Limited 2022 